\title{
The Requirements for Laparoscopy-Assisted Distal Gastrectomy to Become Standard Procedure for Gastric Cancer: Based on Qualitative Study of Surgeons' Experiences
}

\author{
Nozomu Murakami ${ }^{1 *}$, Kouichi Tanabe², Shinichi Kadoya1, Masanari Shimada1, \\ Katsuo Shimada ${ }^{3}$, Masahide Kaji ${ }^{4}$, Mitsuaki Sakatoku5, Koichiro Sawada1, \\ Hatsuna Yasuda ${ }^{2}$, Tatsuhiko Kashii ${ }^{2}$ \\ ${ }^{1}$ Department of Surgery, Saiseikai Takaoka Hospital, Toyama, Japan \\ ${ }^{2}$ Department of Medical Oncology, Toyama University Hospital, Toyama, Japan \\ ${ }^{3}$ Department of Surgery, Imizu Municipal Hospital, Toyama, Japan \\ ${ }^{4}$ Department of Surgery, Toyama Prefectural Central Hospital, Toyama, Japan \\ ${ }^{5}$ Department of Surgery, Tonami General Hospital, Toyama, Japan \\ Email: nozomu1231@takaoka-saiseikai.jp
}

Received 11 March 2014; revised 5 April 2014; accepted 13 April 2014

Copyright (C) 2014 by authors and Scientific Research Publishing Inc.

This work is licensed under the Creative Commons Attribution International License (CC BY). http://creativecommons.org/licenses/by/4.0/

\section{Open Access}

\section{Abstract}

Laparoscopy-assisted distal gastrectomy (LADG) has become one of the standard surgical procedures for gastric cancer in Japan and Korea. However, LADG is currently listed as being in the clinical research phase under the Gastric Cancer Treatment Guidelines. The aim of this study is to report surgeons' opinions of what is needed if LADG is to become a standard procedure. We conducted questionnaire survey with open questions in hospitals that either applied or did not apply LADG and compared the answers. We labeled and categorized the collected data using content analysis. The number of hospitals which applied LADG more than doubled from 5 to 12 hospitals over 3 years. Overall, hospitals reported that the necessary elements for LADG to become a standard procedure are: clinical trials of LADG $(n=5,22.7 \%)$, surgeons' practical experience in performing LADG $(n=4,18.2 \%)$, stability of radical treatment $(n=4,18.2 \%)$, and a shorter operative duration $(n=3,13.6 \%)$ for the procedure. Surgeons' practical experience was chosen as the most important requirement in the hospitals which applied LADG while clinical trials $(n=2,40.0 \%)$ and stability of radical treatment $(n=2,40.0 \%)$ were the most common answers in the hospitals which did not apply LADG. Hospitals and surgeons' practical experience, stabilizing radical cure, and the large scale of clinical trials are for LADG to become a standard procedure and to gain 
equivalent importance as open distal gastrectomy in treating gastric cancer.

Keywords Laparoscopy, Questionnaire Survey, Content Analysis, Open Distal Gastrectomy, Surgical
Procedure

\section{Introduction}

Laparoscopy-assisted distal gastrectomy (LADG) has garnered interest as a surgical procedure for gastric cancer that is noninvasive and that offers better postoperative outcomes than other available procedures [1]-[4]. It has recently become a standard procedure in Japan and Korea [5]-[8]. According to data collected by the Japan Society for Endoscopic Surgery, laparoscopy-assisted gastrectomy (LAG) for gastric cancer/submucosal gastric tumors was performed on more than 7900 patients, and in 2009, 60\% of hospitals in Japan [9] used laparoscopic surgery. LADG was the most commonly performed procedure among various types of LAG in Japan. However, LADG is currently listed in the clinical research phase under the Gastric Cancer Treatment Guidelines; as such, careful management and study are needed before that LADG is disseminated as a standard procedure [10]. No study has reported the state of introduction/annual changes in individual areas or hospitals in Japan, or individual hospitals'/surgeons' opinions regarding LADG. The purpose of our study was to learn surgeons' opinions about what requirements should be met before LADG become a standard procedure and to learn about changes in its application after a period of 3 years. With this aim, we conducted a questionnaire survey with open-ended columns at the 2012 Toyama Surgical Procedure Conference and compared it with a similar survey taken in 2009 using content analysis.

\section{Methods}

\subsection{Subjects}

We surveyed the chairs of the surgery departments at Japanese hospitals that are affiliated with Toyama Surgical Procedure Conference to clarify the current introduction of LADG in Toyama Prefecture. We surveyed 14 hospitals in 2009 and 17 hospitals in 2012 with an open-ended questionnaire. The surgeons who participated in our study consented to cooperate with the study by submitting the survey. Surgeons from 13 out of 14 hospitals we surveyed in 2009 and from all 17 hospitals in 2012 cooperated with the survey.

\subsection{Questionnaire}

In 2012, we asked surgeons at the hospitals which applied LADG and surgeons at the hospitals which did not apply LADG about 1) their standard surgery for gastric cancer, 2) what they thought was required for LADG to become a standard procedure with an open-ended questionnaire, and 3) the merits and limitations of LADG compared with open distal gastrectomy (ODG) (only for the surgeons who had experience with LADG). The questionnaire included items to show the background of the hospitals in our survey (shown in Table 1 and Table 2). We also added the item “Diagnosis Procedure Combination (DPC) system introduction”. The DPC system is a Japanese comprehensive medical payment system that decides method of medical payment responsibility by assigning patients a diagnostic group and can shorten a patient's hospital stay after LADG according to the DPC coding [11].

\subsection{Statistical Analysis}

The Student's t-test and the Chi-square test were used to analyze for significant differences in the background of the participating Toyama hospitals we surveyed in 2009 and 2012 (Table 1). The data we collected from the two questionnaire surveys was analyzed and compared using the Student's t-test, the Chi-square test and Yates' chi-squared test where appropriate to test significant differences in LADG application after 3 years had passed (Table 2). 
Table 1. Background of hospitals which cooperated with the survey.

\begin{tabular}{lccc}
\hline \multicolumn{1}{c}{ Item } & 2009 & 2012 & \multirow{2}{*}{ P value } \\
\cline { 2 - 3 } & $(\mathrm{N}=14)$ & $(\mathrm{N}=17)$ & $0.73^{*}$ \\
No. of registered beds, mean \pm SD & $392 \pm 169$ & $370 \pm 177$ & $0.93^{*}$ \\
No. of surgeons, mean \pm SD & $6.1 \pm 2.6$ & $6.1 \pm 2.9$ & $0.95^{\dagger}$ \\
Hub Hospital in the Oncology Care Network (n, yes/no) & $9 / 5$ & $10 / 7$ & $1.00^{\dagger}$ \\
DPC introduction (n, yes/no) & $12 / 2$ & $15 / 2$ & \\
\hline
\end{tabular}

*Student's t-test, ${ }^{\dagger}$ Chi-square test. DPC: Diagnosis Procedure Combination.

Table 2. 2009 and 2012 questionnaire data.

\begin{tabular}{|c|c|c|c|}
\hline & 2009 & 2012 & \\
\hline & $(\mathrm{N}=14)$ & $(\mathrm{N}=17)$ & P value \\
\hline Introduction of LADG (n, yes/no/unknown) & $5 / 9 / 0$ & $12 / 5 / 0$ & $0.11^{\ddagger}$ \\
\hline Patients for whom LADG was indicated (n, \%) & & & \\
\hline cMNO & $0(0)$ & $0(0)$ & \\
\hline IA & $6(60.0)$ & $8(50.0)$ & $0^{\circ} 0^{\ddagger}$ \\
\hline IB & $3(30.0)$ & $6(37.5)$ & 0.30 \\
\hline II & $1(10.0)$ & $2(12.5)$ & \\
\hline Extent of lymph node dissection in patients undergoing LADG (n, yes/no/unknown) & $2 / 10 / 2$ & $0 / 14 / 3$ & $0.27^{\dagger}$ \\
\hline Reconstruction in patients undergoing LADG (n, \%) & & & \\
\hline Billroth I & $8(57)$ & $8(53)$ & \\
\hline Billroth I/Roux-en-Y & $4(29)$ & $6(40)$ & $0.97^{\ddagger}$ \\
\hline Billroth I/Billroth II & $2(14)$ & $1(7)$ & \\
\hline Duration of LADG surgery (hours), mean \pm SD & $4.35 \pm 0.99$ & $4.05 \pm 0.81$ & $0.57^{\dagger}$ \\
\hline Average length of hospital stay after LADG (day), mean \pm SD & $12.1 \pm 2.25$ & $15.25 \pm 2.61$ & $0.03^{* \dagger}$ \\
\hline LADG-related increase in the incidence of complications (n, yes/no/unknown) & $0 / 4 / 10$ & $2 / 8 / 7$ & $1.00^{\ddagger}$ \\
\hline Could LADG become a standard treatment in the future? (n, yes/no/unknown) & $7 / 7 / 0$ & $13 / 1 / 3$ & $0.03^{* \ddagger}$ \\
\hline
\end{tabular}

Values are presented as $\mathrm{n}$ or mean $\pm \mathrm{SD} .{ }^{*} \mathrm{P}<0.05$ is significant difference, ${ }^{\dagger}$ Student’s t-test, ${ }^{\ddagger}$ Chi-square test, Yates corrected. LADG: laparoscopy-assisted distal gastrectomy. ODG: open distal gastrectomy.

\subsection{Content Analysis}

We divided the cooperating hospitals into 2 groups: hospitals which applied LADG and hospitals which did not apply LADG, and compared our 2012 survey results with those of a similar questionnaire survey carried out 3 years previously at the conference. We selected the responses to the open-ended questions about requirements for LADG to become a standard procedure and the merits and limitations of LADG compared with ODG from hospitals which applied LADG and which did not apply LADG (Table 3, Table 4) and labeled and categorized them according to the content analysis method [10].

\section{Results}

The survey collection rate was 100\%. 14 hospitals responded in 2009 and 17 hospitals responded in 2012.

\subsection{Background of Hospitals Which Cooperated with the Survey}

The number of hospitals which introduced the DPC system increased between 2009 and 2012, but the data did not show significant differences. The other background contents of hospitals also did not show any significant differences after 3 years (Table 1 ). 
Table 3. Requirements for LADG to become standard procedure.

\begin{tabular}{|c|c|c|}
\hline \multirow{3}{*}{ Requirements } & hospitals which applied LADG & hospitals which did not apply LADG \\
\hline & No. of responded hospitals $=12$ & No. of responded hospitals $=5$ \\
\hline & $(\mathrm{n})$ & $(\mathrm{n})$ \\
\hline Surgeons' practical experience & 4 & \\
\hline Large number of clinical trials & 3 & 2 \\
\hline Safety of procedure & 3 & \\
\hline Stability of radical treatment & 2 & 2 \\
\hline Shorten operative duration & 2 & 1 \\
\hline Appropriate application of LADG & 2 & \\
\hline Social recognition & 1 & \\
\hline Total & 17 & 5 \\
\hline
\end{tabular}

LADG: laparoscopy-assisted distal gastrectomy.

Table 4. Merits and limitations of LADG compared to ODG reported by surgeons in the hospitals which applied LADG.

\begin{tabular}{|c|c|c|c|c|c|}
\hline Merits & $\mathrm{n}$ & $\%$ & Limitations & $\mathrm{n}$ & $\%$ \\
\hline Magnified vision effects & 4 & 25.0 & Prolonged duration of surgery & 5 & 35.7 \\
\hline Early surgical recovery & 3 & 18.8 & Limited surgical field & 2 & 14.3 \\
\hline Cosmetic features & 2 & 12.5 & Instrumental limitations & 2 & 14.3 \\
\hline Wound pain reduction & 2 & 12.5 & Limitations regarding hemorrhage & 1 & 7.1 \\
\hline Lower volume of hemorrhage & 2 & 12.5 & Technical difficulty & 1 & 7.1 \\
\hline Early discharge & 2 & 12.5 & Many surgeons are required & 1 & 7.1 \\
\hline \multirow[t]{2}{*}{ Low incidence of SSI } & 1 & 6.3 & Limited number of surgeons & 1 & 7.1 \\
\hline & & & Unfavorable operating conditions if complications arise & 1 & 7.1 \\
\hline Total & 16 & & & 14 & \\
\hline
\end{tabular}

LADG: laparoscopy-assisted distal gastrectomy. ODG: open distal gastrectomy. SSI: surgical site infection.

\subsection{Comparison of Survey Results from 2009 and 2012}

In the 2012 survey, 12 (70.6\%) of the 17 hospitals reported the clinical introduction of LADG. This percentage was markedly higher than that of the previous survey's $35.7 \%$; this difference was not significant, which was possibly due to the limited number of hospitals studied (Chi-square test, Yates corrected: $\mathrm{P}=0.11$ ) (Table 2).

There are two significant differences showed in Table 2: one is the average length of hospital stay after the LADG procedure, which was extended (Student's t-test: $\mathrm{P}=0.03$ ), and the another is the possibility of LADG becoming a standard procedure in future, which increased from 7 hospitals to 13 hospitals reporting the possibility (Chi-square test, Yates corrected: $\mathrm{P}=0.03$ ). Otherwise, there were no significant differences between the survey responses.

\subsection{Comparison of Requirements for LADG as a Standard Procedure}

We compared hospitals which applied LADG and which did not apply LADG about their opinion of the requirements needed to be met before LADG becomes a standard procedure. The requirement cited the most by the hospitals which applied LADG was the necessity of surgeons' practical experience $(n=4)$, and the next most frequent requirements listed were the need for a large number of clinical trials and the necessity of insuring the safety of the procedure. ( $n=3$, respectively, Table 3 ). On the other hand, the hospitals which did not apply LADG cited the need for a large number of clinical trials and for the stability of radical treatment as the most important requirements $(\mathrm{n}=2)$, followed by "shorten operative duration" as the next most important requirement $(\mathrm{n}=2$, Table 3$)$. 


\subsection{Merits and Limitations of LADG Comparing to ODG}

Surgeons from the hospitals which applied LADG cited magnified vision effects as the greatest merit of LADG compared with ODG $(\mathrm{n}=4,25 \%$, Table 4). The second merit they listed was early surgical recovery $(\mathrm{n}=3$, 18.8\%). In contrast, most surgeons cited the long operating time of LADG as a limitation $(n=5,35.7 \%)$ followed by limited surgical field and instrumental limitations $(n=2,14.3 \%$, respectively).

\section{Discussion}

This study is the first to show the importance of obtaining a qualitative analysis of surgeons' experience with and opinions of LADG in an area where hospitals which applied LADG have more than doubled over 3 years. The most important factor in this study is that surgeons with LADG experience and without LADG experience each noted different requirements for LADG to become a standard procedure. This implies that each phase in the process of LADG becoming a standard procedure will require flexible provisions for surgeons with and without LADG experience. The hospitals which did not apply LADG stated the importance of clinical trials and stability of radical treatment as the top requirements for LADG to become a standard procedure. On the other hand, the hospitals which applied LADG stated surgeons' practical experience, clinical trials and stability of radical treatment as the requirements for LADG to become a standard procedure. The results showed that psychological factors, such as the belief that LADG is unreliable, were a barrier to making LADG a standard procedure in the hospitals which did not apply it although the previous studies have showed LADG as equivalently safe as ODG [6] [12]-[17]. Therefore, it is important to run clinical trials to show that LADG is as safe as ODG and to disseminate the trial results. After psychological barriers to the implementation of LADG are eliminated by such clinical trials, it will be necessary to prepare a training program in the LADG procedure to improve surgeons' practical experience. Furthermore, it will be important to test the efficacy of these training programs.

The second important factor in our study was that the merits of LADG evaluated by surgeons at the hospitals which applied LADG contributed largely to patients' QOL. On the other hand, the limitations of LADG were material and human resources such as facilities, equipment, and surgeons' inexperience. As mentioned earlier, a training program could address these limitations.

As for the rest of the factors, the Gastric Cancer Treatment Regulations and Gastric Cancer Treatment Guidelines were revised in 2010, respectively. In the previous version, the group of lymph-node metastases was decided by the number of metastases. Therefore, for staging, the old regulations set forth in Gastric Cancer Treatment Regulations Version 13 were utilized to match the two surveys. The extent of lymph node dissection was evaluated as D1 and D1+ which narrowed the extent in accordance with the Gastric Cancer Treatment Guidelines Version 3, but there was no significant difference in the two surveys $(P=0.27$, Table 2$)$.

The average length of hospital stay after LADG extended in the 3 years between surveys, and was significantly different (as shown in Table 2) although early surgical recovery was one of the merits of LADG procedure. Since the medical service fee payment system was revised between 2009 and 2012, early hospital discharge could have an effect on hospital revenue. Hospitals tend to accelerate hospital discharge at the beginning of the DPC system introduction because they are not used to coding with DPC. The early hospital discharge as a result of DPC coding could cause a decline in hospital revenue. The economic demand from the Medical Professions Divisions to extending hospital stays as long as possible after the LADG procedure to maintain hospital revenue that could affect the results in Table 2, which showed a significant difference despite expected results $(\mathrm{P}=0.03)$. This dilemma between early hospital discharge after LADG procedure and financial pressure from hospital management will be solved when the national length of the hospital stay after LADG is standardized and the hospital stay in division of medical service fee system is revised every time.

This study has two limitations: first, the sample size is small. Second, the survey area is limited so that the generalizability of these survey results is not guaranteed. Nevertheless, this study gave significant insight into surgeons' and hospitals' opinions of the requirements needed for LADG to become a standard procedure. The surgeons who had experience with LADG found many advantages for QOL with LADG, and the limitations noted for LADG were most commonly due to surgeons' lack of practical experience. These factors indicated the need for the development of a LADG training program for surgeons.

\section{Acknowledgements}

This study was performed with the understanding and cooperation by all hospitals participating in the Toyama 
Surgical Procedure Conference. We thank the persons concerned. In this study, there is no conflict of interest (COI) to be disclosed.

Hospitals which cooperated with this survey:

Saiseikai Takaoka Hospital, Toyama prefecture

Imizu Municipal Hospital

Tonami General Hospital

Toyama Prefectural Central Hospital

Toyama City Hospital

Toyama Red Cross Hospital

Toyama University Hospital

Takaoka City Hospital

Kouseiren Takaoka Hospital

Saiseikai Toyama Hospital

Kouseiren Namerikawa Hospital

Kurobe City Hospital

Yatsuo General Hospital

Toyama Rosai Hospital

Hokuriku Central Hospital

Shinseikai Toyama Hospital

Himi Municipal Hospital of Kanazawa Medical University

\section{References}

[1] Kitano, S., Shiraishi, N., Kakisako, K., Yasuda, K., Inomata, M. and Adachi, Y. (2002) Laparoscopy-Assisted Billroth-I Gastrectomy (LADG) for Cancer: Our 10 Years’ Experience. Surgical Laparoscopy Endoscopy \& Percutaneous, 12, 204-207. http://dx.doi.org/10.1097/01.SLE.0000017663.43677.6E

[2] Adachi, Y., Suematsu, T., Shiraishi, N., Katsuta, T., Morimoto, A., Kitano, S. and Akazawa, K. (1999) Quality of Life after Laparoscopy-Assisted Billroth I Gastrectomy. Annals of Surgery, 229, 49-54.

[3] Shimizu, S., Uchiyama, A., Mizumoto, K., Morisaki, T., Nakamura, K., Shimura, H. and Tanaka, M. (2000) Laparoscopically Assisted Distal Gastrectomy for Early Gastric Cancer: Is It Superior to Open Surgery? Surgical Endoscopy, 14, 27-31. http://dx.doi.org/10.1007/s004649900005

[4] Song, K.Y., Kim, S.N. and Park, C.H. (2008) Laparoscopy-Assisted Distal Gastrectomy with D2 Lymph Node Dissection for Gastric Cancer: Technical and Oncologic Aspects. Surgical Endoscopy, 22, 655-659. http://dx.doi.org/10.1007/s00464-007-9431-5

[5] Kitano, S., Iso, Y., Moriyama, M. and Sugimachi, K. (1994) Laparoscopy-Assisted Billroth I Gastrectomy. Surgical Laparoscopy \& Endoscopy, 4, 146-148.

[6] Kim, M.C., Kim, K.H., Kim, H.H. and Jung, G.J. (2005) Comparison of Laparoscopy-Assisted by Conventional Open Distal Gastrectomy and Extraperigastric Lymph Node Dissection in Early Gastric Cancer. Journal of Surgical Oncology, 91, 90-94. http://dx.doi.org/10.1002/jso.20271

[7] Shiraishi, N., Yasuda, K. and Kitano, S. (2006) Laparoscopic Gastrectomy with Lymph Node Dissection for Gastric Cancer. Gastric Cancer, 9, 167-176. http://dx.doi.org/10.1007/s10120-006-0380-9

[8] Kim, Y.W., Baik, Y.H., Yun, Y.H., Nam, Y.H., Kim, D.H., Choi, I.J. and Bae, J.M. (2008) Improved Quality of Life Outcomes after Laparoscopy-Assisted Distal Gastrectomy for Early Gastric Cancer: Results of a Prospective Randomized Clinical Trial. Annals of Surgery, 248, 721-727.http://dx.doi.org/10.1097/SLA.0b013e318185e62e

[9] Japan Society for Endoscopic Surgery. (2013) 10th Nationwide Survey of Endoscopic Surgery in Japan Web site. http://www.jses.or.jp/question/no11/index2.html

[10] Kitano, S., Shiraishi, N., Uyama, I., Sugihara, K., Tanigawa, N. and the Japanese Laparoscopic Surgery Study Group. (2007) A Multicenter Study on Oncologic Outcome of Laparoscopic Gastrectomy for Early Cancer in Japan. Annals of Surgery, 245, 68-72. http://dx.doi.org/10.1097/01.sla.0000225364.03133.f8

[11] Yasunaga, H., Ide, H., Imamura, T. and Ohe, K. (2005) Impact of the Japanese Diagnosis Procedure Combination-Based Payment System on Cardiovascular Medicine-Relate Costs. International Heart Journal, 46, 855-866. http://dx.doi.org/10.1536/ihj.46.855

[12] Shiraishi, N., Adachi, Y., Kitano, S., Bandoh, T., Katsuta, T. and Morimoto, A. (1999) Indication for and Outcome of Laparoscopy-Assisted Billroth I Gastrectomy. British Journal of Surgery, 86, 541-544. 
http://dx.doi.org/10.1046/j.1365-2168.1999.01083.x

[13] Adachi, Y., Shiraishi, N., Shiromizu, A., Bandoh, T., Aramaki, M. and Kitano, S. (2000) Laparoscopy-Assisted Billroth I Gastrectomy Compared with Conventional Open Gastrectomy. Archives of Surgery, 135, 806-810. http://dx.doi.org/10.1001/archsurg.135.7.806

[14] Yacoub, D., Athanasiou, T., Tekkis, P. and Hanna, G.B. (2009) Laparoscopic Assisted Distal Gastrectomy for Early Gastric Cancer: Is It an Alternative to the Open Approach? Surgical Oncology, 18, 322-333. http://dx.doi.org/10.1016/j.suronc.2008.08.006.

[15] Kotake, M., Murakami, N., Tawaraya, K., Yoshino, Y., Koizumi, H., Morita, K., Bandou, H. and Yamada, T. (2004) Comparative Studies between Laparoscopy-Assisted Distal Gastrectomy and Open Distal Gastrectomy. Asian Journal of Endoscopic Surgery, 10, 203-207.

[16] Katai, H., Sasako, M., Fukuda, H., Nakamura, K., Hiki, N., Saka, M., Yamaue, H., Yoshikawa, T. and Kojima, K. (2010) Safety and Feasibility of Laparoscopy-Assisted Distal Gastrectomy with Suprapancreatic Nodal Dissection for Clinical Stage I Gastric Cancer: A Multicenter Phase II Trial (JCOG 0703). Gastric Cancer, 13, 238-244. http://dx.doi.org/10.1007/s10120-010-0565-0

[17] Murakami, N., Kadoya, S., Shimada, M., Endo, N., Ishiguro, K., Sawada, K., Tanabe, K., Yasuda, H., Inaki, N., Yamada,T., Kanehira, E. and Kashii, T. (2014) Open Distal Gastrectomy versus Laparoscopic Distal Gastrectomy: As Influenced by Facility Background Factors in the Real World. Surgical Science, 5, 97-104. http://dx.doi.org/10.4236/ss.2014.53019 